\title{
The population of spotted cuscus (Spilocuscus maculatus) and its habitat carrying capacity in Numfor Island, Papua, Indonesia
}

\author{
ANTON SILAS SINERY ${ }^{1, \bullet}$, WARTIKA ROSA FARIDA ${ }^{2}$, JACOB MANUSAWAI ${ }^{1}$ \\ ${ }^{1}$ Faculty of Forestry, State University of Papua. Jl. Gunung Salju, Amban, Manokwari Barat, Manokwari-98314, West Papua, Indonesia. Tel. \& Fax.: \\ +62-986-211364, ”email: anton_sineri@yahoo.com \\ ${ }^{2}$ Zoology Division, Research Center for Biology, Indonesian Institute of Sciences, Cibinong, Bogor-16911, West Java, Indonesia
}

Manuscript received: 31 August 2015. Revision accepted: 14 April 2016.

\begin{abstract}
Sinery AS, Farida WR, Manusawai J. 2016. The population of spotted cuscus (Spilocuscus maculatus) and its habitat carrying capacity in Numfor Island, Papua, Indonesia. Biodiversitas 17: 315-321. The purpose of this research was to study the population of spotted cuscus (Spilocuscus maculatus) and the carrying capacity of its habitat. The result showed that the cuscus population size in 105 ha research area was 17 individuals, with population density of 0.41 individuals/ha or each individual occupied 2.44 ha. Cuscus is the first consumer in a food chain system that consumes a variety of plants and plays an important role in the spread of plant seeds. Its birth rate is higher than its death rate despite its low reproduction rate. Fruit-bearing trees with diameter $\geq 10 \mathrm{~cm}$ as source of food for cuscus consisted of 13 species of 10 families with a diversity index of 2.43 (categorized as moderate). The productivity of cuscus food was $0.75 \mathrm{~kg} / \mathrm{season} /$ ha which indicated the limitations of the carrying capacity of cuscus' habitat so that the need of food was fulfilled from secondary forests and community gardens.
\end{abstract}

Keywords: Habitat, population, spotted cuscus, Numfor Island

\section{INTRODUCTION}

Cuscus population size in the wild is not well-know, but of the seven species of cuscus in Papua, Spilocuscus maculatus is thought to have large enough populations. According to Sinery et al. (2012), Phalanger orientalis dominates the natural forest area $(0.37$ ha/individual $)$, especially in the open populations such as in Arfak Mountains, while Phalanger gymnotis and S. maculatus, each occupies only 0.10 ha/individual and 0.09 ha/individual. Its condition is influenced by species adaptation abilities to habitat and caused by low reproduction rate and habitat productivity to support the population of $S$. maculatus in Numfor Island.

Numfor Island with an area of $32,580.49$ ha is one of the islands with relatively rich natural resources. Administratively, Numfor Island includes sub-districts of West Numfor, Orkeri, East Numfor, Poiru, and Bruyadori with a population of 9,732 people $(2,105$ households). The island has a relatively flat topography with altitudes ranging from 10 to $205 \mathrm{~m}$ asl (Sinery 2002). As one of the isolated regions, Numfor has biodiversity with a fairly high degree of endemicity, especially for the species of birds, so that the island has been called endemic bird areas (Petocz 1989). About 42 species of birds have been found in this island, including a black head parrot, king prawns, longtailed starling, cockatoos, and bayan. Other wildlife, such as squirrels, bats and coconut crabs have been recorded too. The forest in this island stores various plant species which is home of various wildlife species and orchids, and the place for public hunting activities (Sinery 2015).

The fact shows that the rapid development and population growth encourages increasing forest clearing on this island. According to Sinery (2013), forest in Numfor has been cleared by the community for agriculture, plantation, building materials, and sources of energy (fire woods). Forest conversion in Numfor for agricultural activities, especially the green beans is large.

This study aimed to study the condition of the cuscus population and the carrying capacity of its habitat in the Island of Numfor.

\section{MATERIALS AND METHODS}

\section{Area study}

Sampling area was set in the middle of the villages of Namber, Kansai, and Yenmanu of Numfor Island, Papua, Indonesia with the area of 105 ha at $134^{\circ} 47^{\prime} 35^{\prime}$ ' $\mathrm{E}$ and $0^{\circ}$ $55^{\prime} 57$ ' $S$. The duration of the study was 6 months, from September 2014 to February 2015. Monitoring began by making transects positioned perpendicular to baseline (highway $1000 \mathrm{~m}$ ), parallel to the coastline (crossing the contour line) from West to East in the West Numfor. The baseline was divided proportionally into six transects with an inter-transect distance of $200 \mathrm{~m}$. The first transect was located at the starting point of the baseline $(0 \mathrm{~m})$ and the last transect was set at baseline endpoint $(1000 \mathrm{~m})$ with elevation 10-17 m asl. Each transect had a length of $3500 \mathrm{~m}$ with elevation 191-205 $\mathrm{m}$ and a width corresponding to minimum viewing distance $(50 \mathrm{~m})$. According to Sinery et al. (2012), the effective width of observation transect for dense forest types is $50 \mathrm{~m}$ ( $25 \mathrm{~m}$ each side of transect), and we should use a narrower measure which is more effective in the observation of the population. 


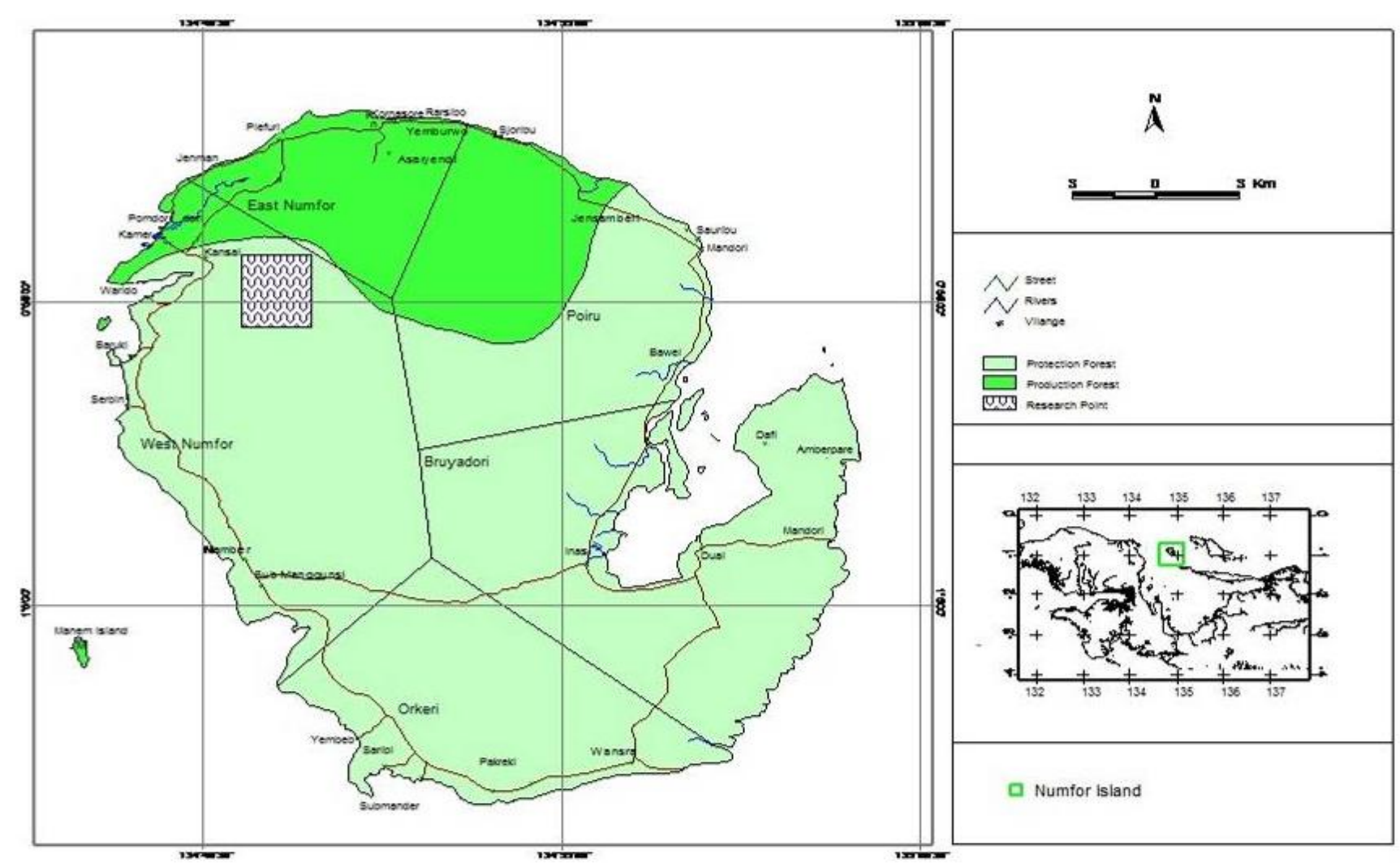

Figure 1. Map of study area in Namber, Kansai, and Yenmanu villages of Numfor Island, Papua, Indonesia

\section{Procedures}

The observations on cuscus was performed simultaneously by 6 groups and each group consisted of 3 people (1 taking note, 1 measuring the distance between the object and transect, and 1 identifying the species of cuscus). The monitoring on cuscus was done three times every two months. The survey was conducted in the night (19:00 to 05:00 CET). According to Sinery et al. (2012), daily activity cuscus occurs at night (7:00 p.m. to 05:00 hours CEST) and is influenced by the weather conditions (rain or not) and the moon.

Cuscus encountered was directly identified according to the morphological characters (color of the body, sex, and age), and the morphological measurements were only performed on adult males and females. The body weight of cuscus was expressed in grams (g) and length of organs in millimeters $(\mathrm{mm})$. The observation was conducted in the home ranges of adult males and females, and started since the animal was found until it slept (morning). To facilitate the measurement of range area, every tree that becomes a displacement of cuscus was labeled yellow, and then GPS tracking during the day was done. Data from cuscus owner related to cuscus reproduction, age, disease, threats from poaching, and other information was collected through interviews.

For vegetation inventory, the method used was terraced path (line plot sampling) which included vegetation seedling (high $\leq .5 \mathrm{~cm}$ ) plots of $2 \times 2 \mathrm{~m}^{2}$, saplings (high $\geq 1.5 \mathrm{~cm}$ and diameter $<10 \mathrm{~cm}$ ) plots of $5 \times 5 \mathrm{~m}^{2}$, pole (diameter 10-19 $\mathrm{cm}$ ) plots of $10 \times 10 \mathrm{~m}^{2}$, and trees (diameter $\geq 20 \mathrm{~cm}$ ) plots of $20 \times 20 \mathrm{~m}^{2}$. The total transects was 6 with a length of $500 \mathrm{~m}$, the distance between the lines was $200 \mathrm{~m}$, and each transect consisted of 25 plots. The vegetation data was used to identify species of plants eaten by cuscus. The data collection for cuscus feed was done during the day, and this activity was also carried out at night simultaneously with cuscus population monitoring. Identification of plant species referred to the key identification of plants and other supporting literature with the help of the identifier of plant species from the Manokwari herbarium.

The production of fruit as food source for cuscus was estimated using in a single plot with the size of $50 \times 50 \mathrm{~m}$ ( $0.25 \mathrm{ha})$. The estimation of fruit production was done by weighing the fruit located under the trees and expressed in $\mathrm{kg} / \mathrm{m}^{2} /$ season or $\mathrm{kg} /$ year. The processing of digital image data was done by analyzing digital image data from Google Maps (2013). The data were then overlaid with Land Cover Map of the region of the Numfor Island for potential forest conditions.

\section{Data analysis}

The data were analyzed using quantitative descriptive method and presented in the form of tabulation and images (charts, graphs, and photographs). The data needed, in accordance with the purposes of research, wew as follows: description of the species of cuscus, population conditions, home range, and ecological niches of cuscus. Cuscus 
morphological data, populations, home range, and ecological niches of cuscus were analyzed using tabulation. Cuscus population density was analyzed by using the equation according to Soegianto (1994), as follow.

$$
\begin{aligned}
& \mathrm{n}(2 \mathrm{n}-1) \mathrm{A} \\
& \mathrm{N}= 2 \mathrm{~L} \text { Ó } \mathrm{r} \\
& \mathrm{N} \quad= \text { population density, } \\
& \mathrm{n} \quad= \text { number of individuals encountered, } \\
& \mathrm{A} \quad= \text { area of region (plot observations) } \\
& \mathrm{L} \quad= \text { length of line/transect, } \\
& \text { Ór } \quad \text { distance from the point where cuscus found to }
\end{aligned}
$$
the line of transect

$$
\begin{aligned}
& \text { Samplingeror }=\sqrt{\operatorname{Var}(\mathrm{N})} \\
& \operatorname{Var}(\mathrm{N})=\left[\frac{\mathrm{n}}{(2 \mathrm{~L} / \mathrm{A} \tau}\right]\left[\left[\frac{3 \mathrm{n}-2}{2(\mathrm{n}-1)(2 \mathrm{~L} / \mathrm{A} \tau)}-1\right]\right] \\
& \tau=(2 \mathrm{n}-1) / \sum \mathrm{r}
\end{aligned}
$$

Vegetation conditions, including plants which produced cuscus feed and other plants, were analyzed to estimate the carrying capacity of the habitat. Analyzes were performed using the equation of Importance Value Index (IVI) according to Mueller-Dombois and Ellenberg (1974), as follows.

$$
\begin{aligned}
& \text { Density }=\frac{\text { Species Individual Total Amount }}{\text { Sample Plot Wide Total Amount }} \\
& \text { Relative Density }=\frac{\text { Species Density }}{\text { All Species Density }} \times 100 \\
& \text { Frequency }=\frac{\text { Plot Total Amount Found the Species }}{\text { All Sample Plot Total Amount }} \\
& \text { Relative Frequency }=\frac{\text { Species Frequency }}{\text { All Species Frequency }} \times 100 \\
& \text { Dominancy }=\frac{\text { The Total Amount of Species Basic Field Wides }}{\text { All Sample Plot Wides }} \\
& \text { Relative Dominancy }=\frac{\text { Species Dominancy }}{\text { All Species Dominancy }} \times 100
\end{aligned}
$$

Importance Value Index (IVI) = Relative Density + Relative Frequency + Relative Dominance

To determine the species diversity of vegetation of which cuscus consumed, as an indicator of habitat's carrying capacity for cuscus population, researchers used species diversity index $(\mathrm{H})$ with the equation according to Shannon and Wiener (1949) in Odum (1993):

$$
\mathrm{H}=-\Sigma\left[\frac{\mathrm{ni}}{\mathrm{N}}\right] \log \left[\frac{\mathrm{ni}}{\mathrm{N}}\right]
$$

Where:

$\mathrm{H}=$ diversity index (Shannon index)

$\mathrm{ni}=$ Number of individuals of each type of feed

$\mathrm{N}=$ Number of individuals of all species feed

Cuscus feed productivity data were used to estimate the carrying capacity of the habitat based on the availability of feed as compared with need of the cuscus population in the study area.

\section{RESULTS AND DISCUSSIONS}

Residents know spotted cuscus in Numfor Island as "Rambab" (male) and "Mifan" (female). Based on the characteristics of the fur color, S. maculatus in Numfor consists of two variations, namely the overall white to dirty white (beige) cuscus and the spotted cuscus. According to Petocz (1994), Flannery (1994), Sinery (2002), there is only one species of cuscus in Island of Numfor, namely the regular spotted cuscus ( $S$. maculatus) which covers two variations (spotted and non-spotted).

The body length (from anterior/head until inferior/tail) of $S$. maculatus male originating from this region ranges between 512 and $550 \mathrm{~mm}$, while its body weight ranges between 4,200 and 5,520 grams. Length and weight of the female body range between 472 and $522 \mathrm{~mm}$ and 3,352 and 4,523 grams. Length and weight of the female body range between 472 and $522 \mathrm{~mm}$ and 3,352 and 4,523 grams. This research showed that $S$. maculatus located in Numfor have the morphological characters that are not much different from that of $S$. maculatus found in other areas in accordance with the results of previous studies. According to Flannery (1994) the body length of the male of this species is between 518 and $550 \mathrm{~mm}$, while its body weight ranges between 2,300 and 6,000 gram and the length and weight of the female body range between 335 and $385 \mathrm{~mm}$ and 3.060 grams. According to Dimomonmau (2000) the body length the male of this species is between 495 and 560 $\mathrm{mm}$, while its body weight ranges between 3,700 and 4,500 gram and the length and weight of the female body range between 485 and $590 \mathrm{~mm}$ and 4.100 and 5.300 grams. Warmetan (2004) states the body length the male of this species is $520 \mathrm{~mm}$, while its body weight is 4.000 gram and the length and weight of the female body range between 470 and $560 \mathrm{~mm}$ and 1.700 and 6.200 grams. According to Jandewoa (2005) the body length the male of this species is between 520 and $610 \mathrm{~mm}$, while its body weight ranges between 3,600 and 4,500 gram and the length and weight of the female body range between 580 and $564 \mathrm{~mm}$ and 3.600 and 5.000 grams. The head of male animal is light brown, spreading from the base of the nose through inter parietal bone toward the back (posterior). The dorsal fur is white with light brown spots on the base of the head towards the back with the darker spot color (dark brown). 


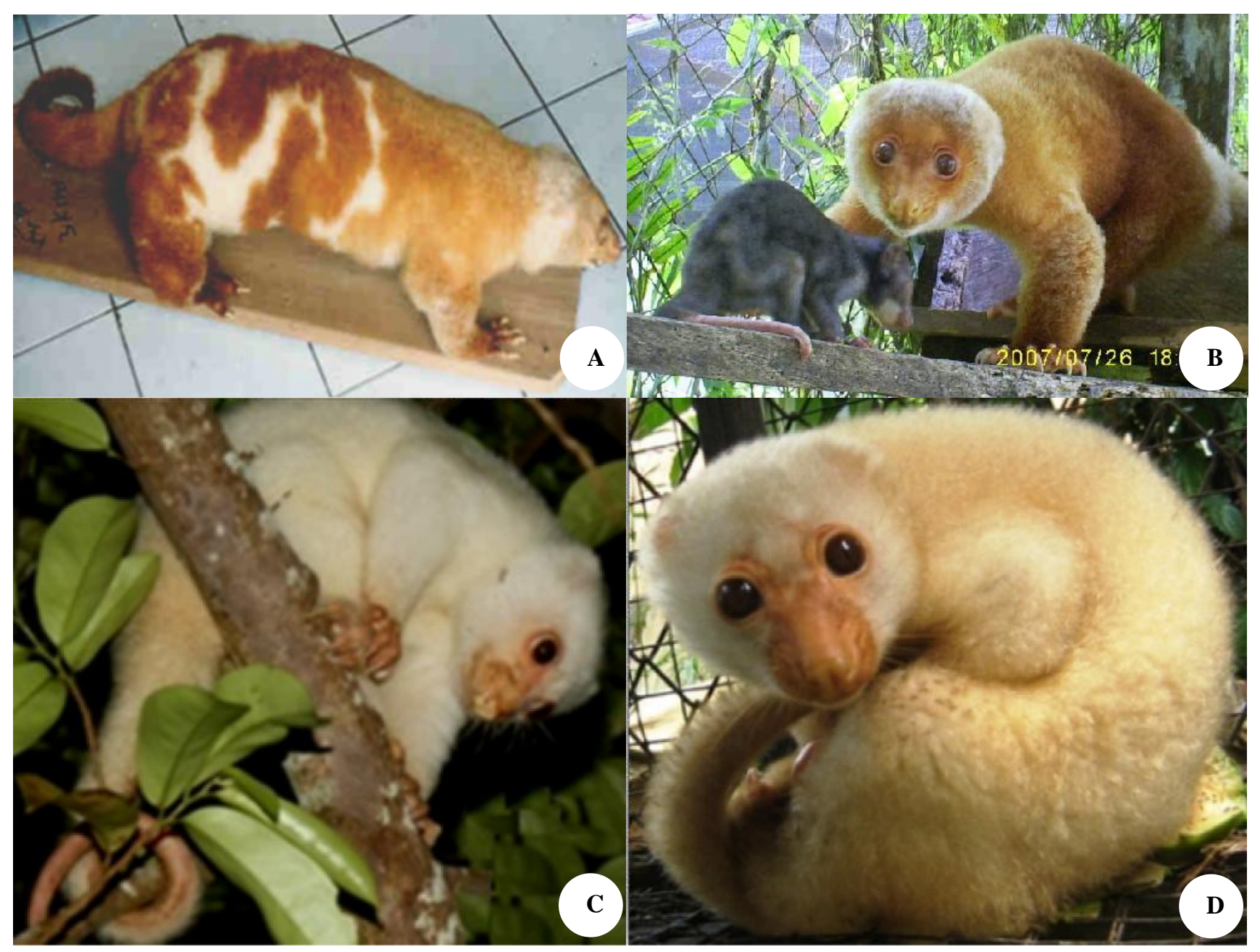

Figure 1. Spilocuscus maculatus from Numfor Island. A. Male/adult, B. Female/adult, C. Male/juvenile, D. Female/juvenile

This color spreads to the side body up to the outside of the legs and hands and ventral boundary. Ventral is light brown (beige) from below the head to the hairy tail's end. The head of female is light brown towards the back (posterior) and forming blackish brown color from the middle of the body (abdomen) to the base of the tail. This color spreads to the body side toward the ventral boundary up to the outside of the legs and arms. The ventral is light brown from under the head to the hairy tail's end with yellowish brown color around the baby bag.

Observational data in the first period, as shown in Table 1 , were used as basic data in the cuscus population analysis, because in the calculation of the population, the researchers made no catching and marking (capturerecapture method) for all individuals encountered. Estimation of population was done through direct observation (encounter).

The small population size in the second and third observation period was allegedly due to adaptation to the availability of sources of feed, mainly in the form of fruit, because cuscus often walked to find alternative feed outside the forest as a substitute of the main feed. In addition, this animal allegedly has the instinct to learn from the experience, and thus tends to avoid areas that have been explored by humans. Cuscuses are solitary animals and sensitive to other activities that disturb their habitat, so that they will turn away and look for another safer place.

The structure of the population is tabulated by age class based on the category of growth that includes juvenile, adolescents and adults, as shown in Table 2.

From 17 cuscuses encountered, 9 (52.94\%) were male and $8(47.06 \%)$ female. The sex ratio of male and female cuscus was almost equal although the number of males was slightly higher. The cuscus population is quite good to be able to exist in the future because the sex ratio is sufficient for the marriage (breeding). It is known that cuscus is polygamous (change partners) with low reproductive ability.

Based on the number of offsprings produced in every reproductive period, researchers found that from two samples that were found both had 1 child, about 1 to 3 week old in the baby pouch. The body length of the cuscus juvenile ranged between 30 and $75 \mathrm{~mm}$.

Based on these results it can be concluded that the average number of juvenile produced by cuscus is low and generally only one child in every reproductive period. According to Menzies (1991), Spilocuscus generally has low reproductive ability that is only one child in every 
reproduction period, so that its population is much lower than the genus of Phalanger.

In general, the number of individuals of adult cuscus is greater than the numbers of the adolescent and the juvenile. The presence of adult cuscus, both male and female, is a good condition for the conservation aspect because of its potential in the process of reproduction and regeneration of the population. Such conditions may occur when environmental components that affect the cuscus population can be controlled or maintained, such as danger from hunting, food availability, and space. Furthermore, the presence of adolescent and juvenile will be the deciding factor for the existence of the population, especially in the process of growth and development in the future.

Estimation of cuscus population density in study plots area of 105 ha was done through comparison of the number of individuals found in the range of distances between cuscus and transects. The cuscus population density is shown in Table 3.

Table 1. Number of individuals cuscus based on frequency observations

\begin{tabular}{llcc}
\hline No & Sex & Individual & Amount \\
\hline Frequency I & Male & 9 & 17 \\
& Female & 8 & \\
Frequency II & Male & 5 & 9 \\
& Female & 4 & 7 \\
Frequency III & Male & 4 & \\
& Female & 3 & \\
\hline
\end{tabular}

Table 2. Number of individuals and age structure of $S$. maculatus in Numfor Island, Papua

\begin{tabular}{|c|c|c|c|c|}
\hline \multirow{2}{*}{ Age class } & \multicolumn{2}{|c|}{ Sex } & \multirow{2}{*}{$\begin{array}{l}\text { Individual } \\
\text { (ni) }\end{array}$} & \multirow{2}{*}{$\begin{array}{c}\text { Percentage } \\
(\%)\end{array}$} \\
\hline & Male & Female & & \\
\hline Juvenile $(<1.5$ years $)$ & 1 & 1 & 2 & 11,76 \\
\hline Adolescent (1.5-3 years) & 2 & 1 & 3 & 17,65 \\
\hline Adult (>3 years) & 6 & 6 & 12 & 70,59 \\
\hline Total amount & 9 & 8 & 17 & 100,00 \\
\hline
\end{tabular}

Notes: Juvenile (neonatal/infant) $=$ individual newborn (baby) including those not yet weaned (at the parent sac); adolescent = immature physically and sexually, already moving on its own but sometimes still with the parent; adult = had matured both physically and sexually and permanent dentition was complete.

Table 3. The population density of cuscus (Spilocuscus maculatus) in Numfor Island, Papua

\begin{tabular}{cccc}
\hline $\begin{array}{c}\text { Number } \\
\text { transection }\end{array}$ & $\begin{array}{c}\text { Total } \\
\text { individual (n) }\end{array}$ & $\begin{array}{c}\text { Cuscus distance } \\
\text { from transection } \\
(\mathbf{m})\end{array}$ & $\begin{array}{c}\text { Population } \\
\text { density }\end{array}$ \\
\hline 1 & 2 & 45 & \\
2 & 6 & 105 & \\
3 & 3 & 52 & \\
4 & 1 & 25 & \\
5 & 3 & 59 & \\
6 & 2 & 36 & 0.41 \\
Total amount & 17 & 322 & \\
\hline
\end{tabular}

Notes: Transection total long $(\mathrm{L})=21,000 \mathrm{~m}$; transection wides $(\mathrm{A})=105 \mathrm{ha}$
The results (Table 3) shows that in the area of 105 ha there were 17 individuals cuscus with a population density of 0.41 individual/ ha or every individual had a control of an area of 2.44 ha. This population density was higher than that in the study of Febriadi (2012) which was 0.31 individuals/ha, as well as with population density of regular spotted cuscus in Arfak Mountains Nature Reserve (Sinery, et al. 2012). The situation was influenced by the concentration of individuals in the forest conditions which were still good in this region. Any increase in the number of individuals will be directly proportional to the total area required for activity. The control of space by the population of regularly spotted cuscus was an area of $322 \mathrm{~m}^{2}$. The number was far greater than that of the population of regularly spotted cuscus in the area of Arfak Mountains Nature Reserve (Sinery et al. 2012). This fact indicates a positive correlation between the condition of space such as the availability of feed and cuscus populations. Monitoring results showed that the presence of cuscus was found more to the center of the area and concentrated in the western part of the island which had a fairly high it altitude with good condition e of vegetation.

The estimation results showed that this population density was higher than that found in the study by Febriadi (2012) which was 0.31 individuals/ha and that in Arfak Mountains according to Sinery et al. (2012). Based on these figures, assuming that the cuscus population spread evenly on the forest that was still good, the number of cuscus in Numfor for forest area that was still good, which was 11597.88 ha, was 4,811 individuals, with the lowest number of 4,689 individuals and the highest number of 4,933 individuals (sampling error/SE $=122$ ).

The cuscus population in this forest is potential to be managed as one of the objects in the development of the area. From the aspect of sustainability, the population can be maintained in the future if there is no more hunting and forest conversion. According to Franklin (1980) at least, 50 individuals are required to maintain genetic diversity in captivity. The number is determined based on experience, that the stock of captive animals can be maintained when the loss of diversity is $2-3 \%$ per year, so the 50 individuals will only lost $1 \%$ of genetic diversity.

Consider these assumptions, the cuscus populations in Numfor Island is rated worrying in the future. The condition arises because in the wild cuscuses do more activities such as eating, mating, and other activities, but the limited food resources and increase in the rate of forest conversion and illegal hunting will lead to the decreasing population of this species.

The estimation minimum area of home range for each individual of cuscus was $2,000 \mathrm{~m}^{2}$ and the maximum was $2,700 \mathrm{~m}^{2}$, so that 17 individuals of cuscus who lived in this area will require a minimum of $86,000 \mathrm{~m}^{2}$ of land ( $8.6 \mathrm{ha}$ ) and a maximum of $116,100 \mathrm{~m}^{2}$ (11.61 ha). According to Sinery et al. (2012), the minimum home range area of individual cuscus in the open population such as in Arfak Mountains Nature Reserve is $1,225 \mathrm{~m}^{2}$ and the maximum is $2,400 \mathrm{~m}^{2}$. These conditions indicate that the carrying capacity of the habitat of cuscus in forested areas in Numfor Island is still good enough for the existing 
population. Modeling based on Soegianto's formula (1994), estimated that as many as 43 individuals of cuscus lived in the effective area in Numfor, Papua.

The development of these animals introduced is quite good and can spread to different areas, but the presence of high mountains caused the concentration of the population in some areas. These conditions do not become an obstacle in the growth and development of populations of native mammals such as cuscus, like conditions of cuscus populations in the island of Numfor.

Cuscus is a nocturnal animal that generally performs activities (foraging, mating, and playing) at night. The results of observation specifically to the example of male and female adult cuscuses from Numfor Island indicated that the active time of cuscuses in Numfor was the time at which cuscuses start doing the activity until they were back to rest/ hide, i.e., from 20:00 to 05:00 CET. The highest frequency of activity of cuscus was eating, followed by urination and defecation.

Time and frequency of eating $S$. maculatus were quite high because the proportion of the required amount of feed intake is in accordance with the size of the body, so that the amount of feed and meal times is relatively high. Based on the level of palatability, cuscus tends to consume the types of feed in the form of ripe fruit. Allegedly, in addition to having sweet taste, ripe fruit also contains much water to ease the digestion process.

Active time of cuscus in Numfor is influenced by rainy conditions and the moon. In both conditions, cuscus will usually do the activities. At the time of rain (at night), cuscus does not perform activities and generally rests and after rain cuscus started to do the activity again. This is because cuscus utilizes fresh feed material with high water content. In addition, when the light of the moon, cuscus rarely do activities, because it avoids other animal species (predators). Cuscus is usually found in the conditions after raining and when the moon shines brightly (Sinery et al. 2012). After the rain, cuscus feed themselves by eating part of the new shoots and performs other activities. In addition, when the moon shines brightly, cuscus takes advantage of moonlight to look for sources of feed and to find partners. Cuscuses are active at night and rest during the day in the grove, holes in the ground, or in the rock crevice. Sometimes this animal rests (sleeps), bends over and hugs branches or tree trunks which are not dense or open (Flannery 1994). The results showed that cuscus is generally found in certain types of location.

According to Sinery (2013), cuscus is a mammal that has a fairly small territory (4 individuals per ha of forest which is still good) and is polygamous with the life span which can reach 13 years, but in captivity, this animal can live up to 15 years. The distribution of age classes of cuscus is the same as in other mammals, which consists of juvenile class ( $<1.5$ years), adolescent class (1.5-3 years), and adult class (>3 years). This animal has a low reproductive capacity, ie one parent only produces one child in every time period of reproduction, with the reproduction frequency of at least 1 time a year. According to Sinery et al. (2012), lower reproductive ability of cuscus is due to the long span of time of feeding or caring for the infant (in the baby bag), namely 6 months, despite having a relatively short gestation period (1.5-2 moon).

Under these conditions, the estimated population growth for the first year after the study is a minimum of 49 individuals, consisting of 43 beginning individuals and 6 new individuals, whereas in the second year the population will grow to 56 individuals consisting of 49 beginning individuals plus 7 new individuals. The population will be greatly developed in the next few years if the component of the environment are maintained or does not experience significant changes, including hunting.

During the execution of the study, researchers did not find mating activities between cuscuses observed. This situation is thought to be caused by the fact that the study was conducted during the dry season which was not mating season for cuscus; generally cuscuses perform mating activity during the rainy season. This is related with the productivity of the cuscus feed. In the rainy season, cuscus feed productivity is high; the feed was abundant, thus supporting the process of reproduction. From a number of cuscus which was found having 1-3 week old babies in their baby pouch/holster, it can be presumed that the mating season had ended. Sinery (2002) mentions that mating activities of cuscus will increase during the rainy season because the availability of food resources in the fruit season. Mating begins with the issuance of a male voice as a signal to females and other males which were in the area of territory. If there is reply (voice) from female cuscus, then the male cuscus will move closer to the female while making the sound. This process takes approximately 15-35 minutes before the mating. Monitoring result showed that at a distance up to $120 \mathrm{~m}$, cuscus was still be able to communicate with each other by issuing sound.

The natural mortality rate of cuscus is lower than its birth rate. The condition is influenced by a relatively long life span of cuscus and also by the absence of natural predators that affect the population of this animal. Population changes will occur with the death of as many as 12 individual cuscuses from age class of adult, and population growth will take place on individual cuscuses from age classes of adolescent and juvenile which later will become mature individuals. Natural mortality of individual's cuscus does not significantly affect the presence of cuscus populations in this region if the other components of the environment can be maintained or does not experience significant changes, including hunting.

The forest area of Numfor Island has different level of plant vegetation. There are 31 species of trees found where first three species with highest important value index (IVI) are Horsfieldia laevigata (31.11\%), Canarium hirsutum (23.99\%) and Palaquium amboinensis (20.30\%). At the poles, there are 27 species of plant where three species with highest IVI are Horsfieldia laevigata (21.66\%), Canarium hirsutum (20.36\%) and Mallotus philippinensis (19.44\%). At the saplings, there are 24 species of plant where three species with highest IVI are Palaquium lobianum (33.29\%), Aglaia sp. (23.45\%) and Lepiniopsis ternatensis $(23.39 \%)$. At the seedling, there are 25 species of plant where three species with highest IVI are Horsfieldia laevigata (19.52\%), Mallotus philippinensis (14.20\%) and 
Pimelodendron amboinicum (11.88\%) (The complete data is not shown).

Source of cuscus feed in the form of fruit-bearing plants (with a diameter of $10 \mathrm{~cm}$ or more) were found as many as 13 species of 10 families with a diversity index of 2.43 (moderate criteria) and productivity of $0,75 \mathrm{~kg} / \mathrm{season} / \mathrm{ha}$. This situation illustrated the potential limitations of the feed so that the fulfillment of the feed shortage was done outside the forest area which was still good (secondary forest and community farm). The average of home range area for each of cuscus was $2000-2700 \mathrm{~m}^{2}$ and the existing population required a minimum area of $9,622,024 \mathrm{~m}^{2}$ area (962.20 ha) and maximum area of 12,989,732 $\mathrm{m}^{2}$ (1298.97 ha) which indicated the presence of carrying capacity of habitat which was good enough. According to Saragih et al. (2010), there were 19 plant species identified as cuscus diets in natural habitat. They prefer fruits with astringent and sour taste as well as high crude fiber and low fat.

\section{ACKNOWLEDGEMENTS}

This research could take place well through the help of various parties either directly or indirectly. Thanks are due to Tropical Forest Research Centre, the University of Mulawarman, Samarinda, East Kalimantan, Indonesia for the help and support given and for the University of Papua and Numfor community that support the implementation of this research.

\section{REFERENCES}

Dimomonmau P. 2000. Exploration of Cuscus at Moor Island Napan Weinami Sub-District, District of Nabire. [Hon. Thesis]. Faculty of Agriculture, University of Cenderawasih, Manokwari. [Indonesian].

Febriadi I. 2012. Study about Habitat and Estimation of Spotted Cuscus Population (Spilocuscus maculatus) at Numfor Island, Biak Numfor District. University of Mulawarman, Samarinda. [Indonesian].

Flannery T. 1994. Possums of the World. A Monograph of the Phalangeroidea. Geo Production Pty Ltd, Australia.

Frangklin IR 1980. Evalutionary change in small populations. In: Soule ME, Wilcox BA (eds). Conservation Biology and Evolutionary Ecological Perspective. Sinauer, Sanderland, MA.

Menzies JI. 1991. A Handbook of New Guinea Marsupials and Monotermes. Kristen Press Inc. Papua New Guinea, Madang

Mueller-Dombois D, Ellenberg H. 1974. Aims and Method of Vegetation Ecology. John Willey and Sons, Toronto.

Odum P. 1993. Fundamentals of Ecology. 3rd ed. Gajah Mada University Press, Yogyakarta [Indonesian].

Petocz RG. 1994. Terrestrial Mamalia of Irian Jaya. PT Gramedia Pustaka Utama, Jakarta. [Indonesian]

Saragih EW, Sadsoeitoeboen MJ, Pattiselanno F. 2010. The diet of spotted cuscus (Spilocuscus maculatus) in natural and captivity habitat. Nusantara Bioscience 2: 78-83.

Sinery A. 2002. Exploration of Cuscus at Numfor Island, District of Biak Numfor. [Hon. Thesis]. Faculty of Forestry, University of Papua, Manokwari. [Indonesian].

Sinery A. 2013. Management Strategies of Cuscus (Spilocuscus maculatus) on the Numfor Island, Papua Province. University of Mulawarman, Samarinda. [Indonesian].

Sinery A. 2015. Management Strategies of Cuscus on the Numfor Island. Deeppublish, Yogyakarta. [Indonesian]

Sinery A, Boer C, Farida W. 2012. The population condition and food availability of cuscus in Arfak Mountains Nature Reserve, West Papua. Biodiversitas 13 (2): 86-91

Soegianto. 1994. Quantitative Ecology: Analysis Methods of Population and Community. Usaha Nasional, Surabaya. [Indonesian]

Warmetan H. 2004. Exploration of Cuscus Species at Central Yapen Nature Reserve and its Surroundings, South Yapen Sub district, District of Yapen Waropen. [Hon. Thesis]. Faculty of Forestry, University of Papua, Manokwari. [Indonesian] 